\title{
Improvement in Oral Health and Compliance in a Child with Congenital Hypothyroidism. Case Report
}

\section{Progreso del cuidado oral y el comportamiento en un niño con hipotiroidismo congénito. Reporte de caso}

Hiram Daniel López-Santacruz DDS¹; Denisse Aidé Herrera-Badillo DDS'; Raúl Márquez-Preciado DDS; Gabriela Torre-Delgadillo DDS'; Miguel Ángel Rosales-Berber DDS ${ }^{1}$

1. Pediatric Dentistry Postgraduate Program, Faculty of Dentistry, San Luis Potosi University, San Luis Potosi, SLP. México.

Correspondence to: Dr. Hiram Daniel López-Santacruz -sthdan@outlook.com

Received: 10-VI-2019

Accepted: 24-VI-2019

Published Online First: 28-VI-2019

DOI: $10.15517 / / J D S .2019 .37850$

\section{ABSTRACT}

Congenital hypothyroidism is a metabolic disorder that requires special health care interventions. It has influence in overall growth and oral conditions in pediatric patients, and also can affect child cooperation during dental treatment because this metabolic condition is the most common preventable cause of mental retardation. The aim of this paper is to report the dental treatment of a child with congenital hypothyroidism who is four years and five months old, with many facial and oral characteristics of the metabolic condition, including severe early childhood caries and malocclusion. At first, it was observed a lack of cooperation of the patient with speech and learning impairment, but with the help of the Pedagogy team at the Pediatric Dental Clinic Playroom, he developed confidence and diminished anxiety every appointment. We present the follow-up during 15 months, where we could observe favorable outcomes in oral health and compliance of the child.

\section{KEY WORDS}

Dental care; Hypothyroidism; Pediatric dentistry; Special health care needs. 


\section{RESUMEN}

El hipotiroidismo congénito es una alteración metabólica que representa una necesidad especial en salud. Tiene influencia en el crecimiento general y las condiciones orales de los pacientes pediátricos, así como también puede afectar en el grado de cooperación del niño durante la consulta porque esta condición metabólica es la causa prevenible más común de retraso mental. El propósito de este artículo es reportar el tratamiento odontológico de un niño con hipotiroidismo congénito de cuatro años y cinco meses de edad, con varias características de la condición metabólica, incluyendo caries de la infancia temprana severa y maloclusión. Al principio se observó una falta de cooperación por parte del paciente, con dificultades para el habla y el aprendizaje, pero con la ayuda del equipo pedagógico de la Sala Lúdica, el niño desarrolló confianza con disminución de la ansiedad en cada cita. Presentamos un seguimiento a lo largo de 15 meses, donde hemos observado resultados favorables en la salud oral y en el comportamiento del paciente.

\section{PALABRAS CLAVE}

Hipotiroidismo; Necesidades especiales; Odontología pediátrica; Salud oral.

\section{INTRODUCTION}

Metabolic and endocrine alterations during childhood are Special Health Care Needs (SCHN), and they require health interventions by multidisciplinary teams to guarantee the best level of well-being possible, which includes optimal preventive and therapeutic goals in oral health (1).

Congenital hypothyroidism $(\mathrm{CH})$ is the most common endocrine disease in pediatric population (2), originated by an inappropriate development of thyroid gland in the most of the cases (3), with a diminished availability of thyroid hormones in tissues and impacting in body metabolism (4). Early detection of $\mathrm{CH}$ is accomplished through newborn screening tests, and it has been identified a global prevalence of approximately 1:4,000 newborns with $\mathrm{CH}$. This tests allow to establish a timely hormone replacement therapy (HRT) $(2,3,5)$.

$\mathrm{CH}$ has influence in four principal aspects of oral health care in the pediatric patients:
- Growth and development. Thyroid hormones act as regulators of bone metabolism and skeletal maturity through endochondral ossification (6). In children with $\mathrm{CH}$, growth pattern could be delayed and be manifested as short stature, brachycephaly and open cranial sutures $(4,7,8)$.

- Patientcooperation. An optimal brain development depends on thyroid hormones during the first three years of life, and $\mathrm{CH}$ is the most common preventable cause of mental retardation (3). So, it is important to make adjustments in behavior guidance (4) and to establish communication strategies with children that are compatible with their cognitive skills (8).

- Oral conditions. Children with $\mathrm{CH}$ may present dental anomalies caused by a reduction of calcium and phosphorus in enamel, this anomalies could range from diffuse opacities to severe enamel hypoplasia. Also, gingival swelling may compromise periodontal health $(2,9,10)$. Malocclusion could occur due to delayed exfoliation of primary teeth and delayed eruption of permanent ones $(11,12)$. 
- General health status. A lack of an adequate HRT in children with $\mathrm{CH}$ could trigger cardiovascular, respiratory, gastrointestinal and neuromuscular affections (4). So, adherence to medical treatment should be assured in order to avoid complications during dental appointment (2).

The aim of this paper is to report the dental treatment of a child with hypothyroidism and the follow up with recommendations for its dental management in pediatric dentistry.

\section{CASE REPORT}

A four year-five months old male attended dental service for the first time at the Postgraduate Pediatric Dentistry Clinic of San Luis Potosi University, San Luis Potosi, Mexico complaining of dental caries accompanied by his mother, who answered the questionnaire of the medical records and signed a written inform consent. The patient was diagnosed with $\mathrm{CH}$ at one year and three months of age because of delayed growth, and he didn't receive the newborn screening tests as he was hospitalized because of thrombocytopenia. Current HRT was Levothyroxine 50 micrograms daily (3). He was considered to be in euthyroid state with favorable evolution, because his thyroid stimulating hormone (TSH) levels and free thyroxine (T4) index were in adequate ranges according to his age. His corporal weight was $15 \mathrm{~kg}$ and his height was $1.00 \mathrm{~m}$. His primary vital signs were: body temperature $36.8^{\circ} \mathrm{C}$, blood pressure $105 / 60$ $\mathrm{mmHg}$, heart rate 92 beats per minute and respiratory rate 20 breaths per minute.

The patients' mother referred that he presented speech and learning impairment, and he was attending language therapy service at that moment. In regard of the nutritional and hygiene habits, he consumed high-carbohydrate diet and he only achieved oral hygiene once a day assisted by his mother. The patient presented oral habits such as frequent lip suction and nocturnal mouth breathing. The extraoral examination revealed a brachycephalic skull with straight profile, and also facial characteristics of hypothyroidism: hypertelorism, periorbital puffiness, wide neck and depressed nasal bridge (Figure 1). The intraoral examination revealed thick lips, gum pigmentation, bilateral mesial step and anterior crossbite. There were observed deep cavities in all primary second molars and primary mandibular right molar. Maxillary central incisors presented enamel hypoplasia (Figure 2).

Due to the extent of the treatment required and patients lack of cooperation, it was explained to the mother the possible use of advanced behavior guidance techniques, such as protective stabilization, sedation or general anesthesia (1). In the first dental appointment it was carried out a dental prophylaxis using basic communication techniques, and the proper brushing technique was explained to the mother, with fluoride toothpaste twice a day (1). Every appointment the child was encouraged to visit the Pediatric Dental Clinic Playroom prior to dental treatment, so he could interact with specialists trained in Pedagogy and learn about dental procedures through games and activities, as he developed confidence and diminished the anxiety (Figure 3) (13).

The dental treatment consisted in pit and fissure sealants in primary maxillary right and primary mandibular left molars, resinbased composite in primary maxillary left molar, pulpotomies in primary maxillary second molars, pulpectomies in primary mandibular second molars, stainless steel crowns in primary maxillary central incisors, primary mandibular right molar and in all primary second molars (Figure 4). In each appointment local anesthesia was achieved with one cartridge of $2 \%$ lidocaine with 1:100,000 epinephrine. Once the dental treatment was finished, it began a follow-up every six weeks for the 
next 15 months, where there was realized dental prophylaxis, brushing techniques reinforcement and fluoride varnish application.

During the last appointments, there were assessed the dental exfoliation of primary mandibular incisors and dental eruption of permanent incisors and permanent first molars by clinical observation and radiographic images. There have been detected enamel opacities in newly erupted permanent teeth (probably hypomineralization), which are in current observation (Figure 5). Overall, dental treatment was achieved successfully using basic communication and guidance behavior techniques.

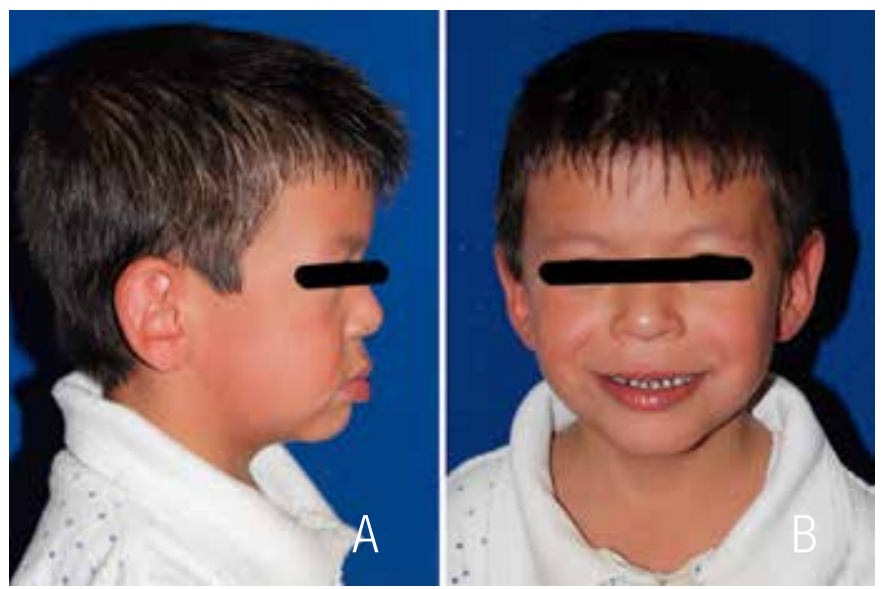

Figure 1. Extraoral examination. (A) Profile view. (B) Frontal view.
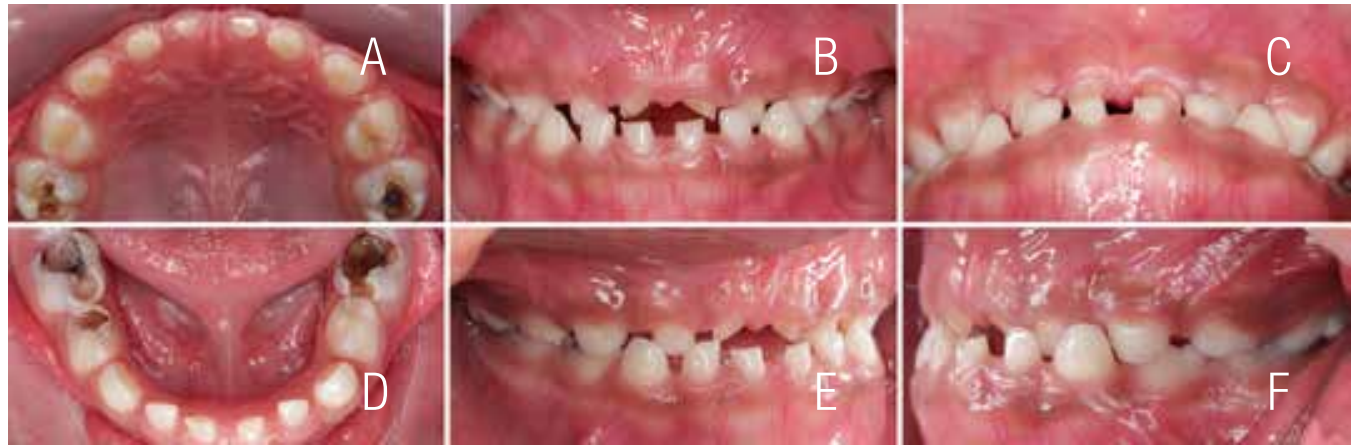

Figure 2. Pre-treatment intraoral examination. (A) Maxillary occlusal view. (B) Frontal view. (C) Overbite. (D) Mandibular occlusal view. (E) Right occlusion. (F) Left occlusion.

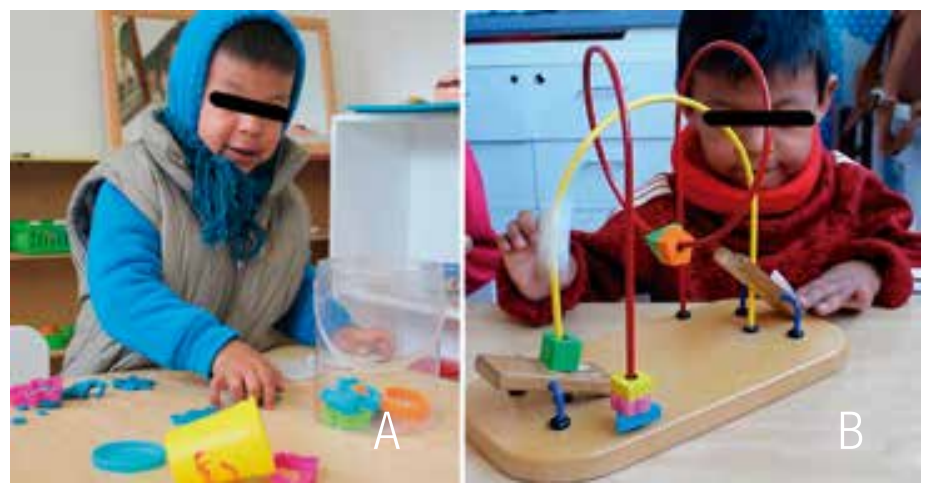

Figure 3. Patient in Pediatric Dental Clinic Playroom. 


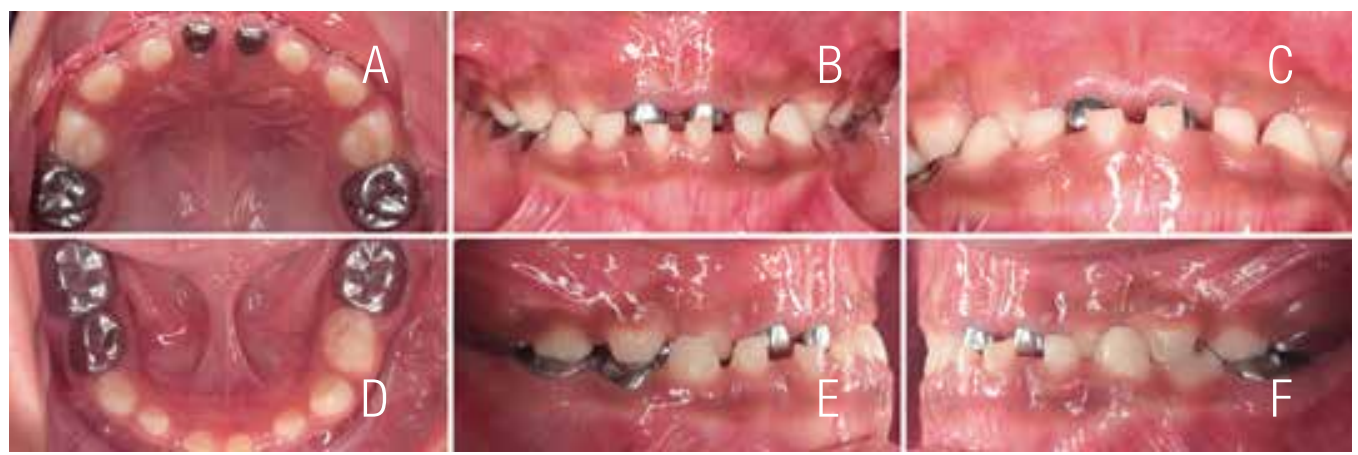

Figure 4. Post-treatment intraoral examination. (A) Maxillary occlusal view. (B) Frontal view. (C) Overbite. (D) Mandibular occlusal view. (E) Right occlusion. (F) Left occlusion.
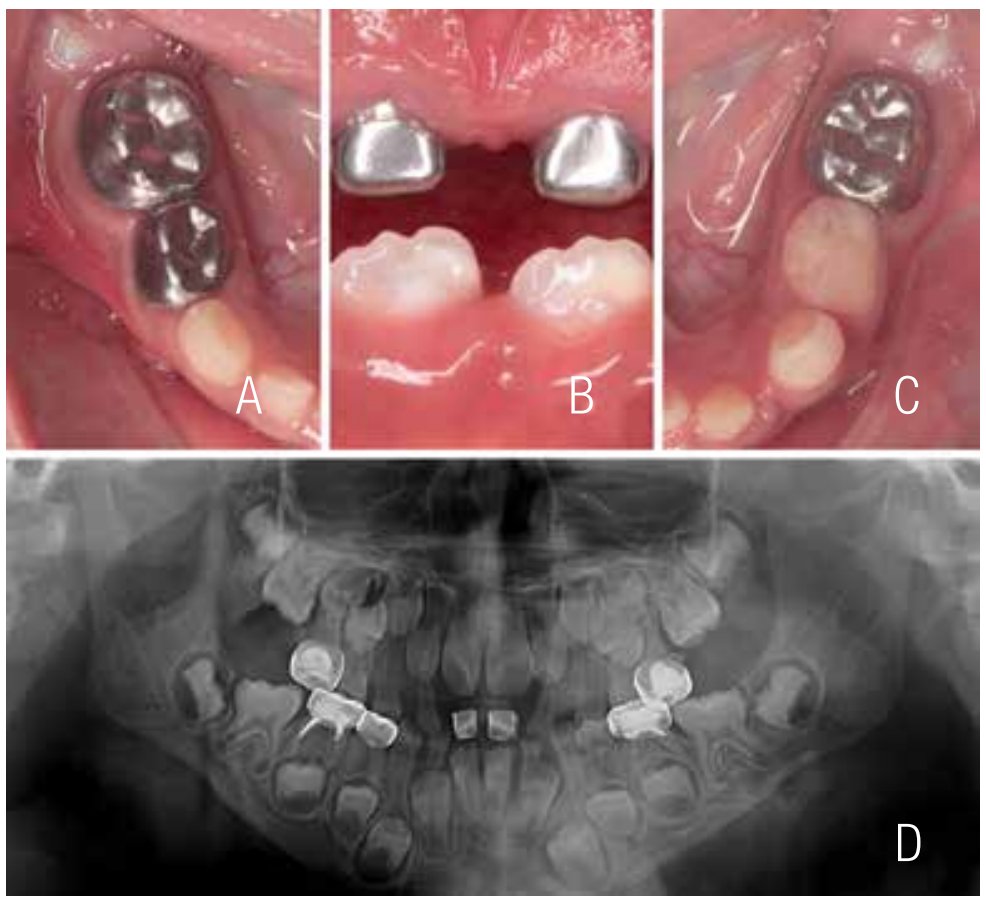

Figure 5. Follow-up of newly erupted permanent teeth with diffuse opacities of enamel. (A) Permanent mandibular right first molar. (B) Permanent mandibular central incisors. (C) Permanent mandibular left first molar. (D) Orthopantomography. 
DISCUSSION

Pediatric Dentistry plays an important role in early detection and diagnosis of thyroid anomalies, so it must be recommended the realization of screening tests for all newborns (10), so appropriate treatment could begin in a timely manner to avoid physical and cognitive development issues and to minimize oral and systemic diseases (1).

The patient was identified to have a metabolic anomaly as he entered to the dental clinic, because of his characteristic physical features (short stature, brachycephalic skull, facial edema) (8), and the medical record answered by his mother confirmed the presence of $\mathrm{CH}$. It is mandatory to be informed about the medical status of patients with endocrine alterations, and basal values must be known in order to recognize a status of hypotension, hypothermia or bradycardia (4). Also, pediatric dentists should encourage patients' follow-up with an endocrinologist.

It must be paid attention to behavior guidance in patients with learning disorders to win their cooperation and to reduce stress, so advanced behavior guidance techniques could be avoided, as pharmacological sedation with midazolam and other Central Nervous System depressants may aggravate lethargy or compromise heart and respiratory rates in patients with $\mathrm{CH}$ (12). In this particular case, there was noticed a favorable development in social, language and cooperative skills because of the time the patient spent at the Clinics Playroom (13) with the guidance of the Pedagogy specialists, and sedation or another advanced technique weren't needed. Also, we instructed the patients' mother to include healthy food in his diet, perform tooth brushing at home after every meal, encourage the child to be more participative and cooperative at the dental clinic, and maintain strict adherence to dental appointments. These recommendations may apply to parents of kids with similar conditions.
Considering that delayed dental eruption is associated with $\mathrm{CH}$, it was prioritary to perform pulp therapies in primary teeth and to restore the masticatory function (2) along with preventive measures. It was decided to restore primary maxillary central incisors with stainless steel crowns due to enamel hypoplasia. At first it was considered to place reversed crowns to correct the anterior crossbite (14), nevertheless, the excessive overjet didn't allow it. For operatory procedures, local anesthesia was achieved with one cartridge of lidocaine with epinephrine, previously corroborated that the patient didn't have any heart disease and limiting anesthetic dose according to patients weight (4).

It was unusually found that primary mandibular central incisors had early exfoliated and permanent central incisors and first molars were already erupting. Those teeth have presented enamel diffuse opacities, possibly associated with molar-incisor hypomineralization (9), so the patient underwent frequent follow-ups and fluoride varnish applications. The future monitoring plan is to assess craniofacial growth and development, management of the developing occlusion and continue with the preventive strategies. It is evident that the patient will require orthodontic intervention (4), which will be started when the patient was considered to be emotionally prepared to cooperate with oral appliances. At age seven, we expect the first permanent molars and permanent incisors to be fully or partially erupted, so we could start maxillary orthopedics to intercept class III malocclusion.

\section{CONCLUSION}

The medical and dental team should offer the best health care to patients with $\mathrm{CH}$, emphasizing the importance of timely medical and dental treatments. On our side, pediatric dentists must teach effective oral hygiene tecnhiques (15), and also ensure patients compliance to dental treatment 
to achieve a caries-free status and avoiding the development of periodontitis in adulthood. Goals must be directed to win a positive cooperation during the appointments to guarantee patients physical and emotional wellbeing (1).

\section{ACKNOWLEDGEMENTS}

We'd like to thank the Pedagogy team at the Pediatric Dental Clinic Playroom for their valuable help in achieving patients' compliance every appointment: Castro-Hernández María del Carmen, Ramírez-Lara Paola Jassive, Esquivel-Hernández Rocío and Briones-González María Jovita.

\section{REFERENCES}

1. Council on Clinical Affairs. Guideline on Management of Dental Patients with Special Health Care Needs. Pediatr Dent. 2016 Oct; 38 (6): 171-176.

2. Ayala C., Lemus O., Frías M. Oral and systemic manifestations of congenital hypothyroidism in children. A case report. Journal Of Oral Research 2015; 4 (5): 329-334.

3. LaFranchi S.H. Approach to the diagnosis and treatment of neonatal hypothyroidism. J Clin Endocrinol Metab. 2011 Oct; 96 (10): 2959-67.

4. Nagar K., Sujatha G.P., Shubha C., Lingappa A. Oral physician: A portal to systemic health through oral health-Acase of hypothyroidism and review of literature. IJOHS. 2018; 8 (1): 39-46.

5. Chaker L., Bianco A.C., Jonklaas J., Peeters R.P. Hypothyroidism. Lancet 2017; 390 (10101): 1550-1562.

6. Vucic S., Korevaar TIM, Dhamo B. et al. Thyroid Function during Early Life and Dental Development. J Dent Res. 2017 Aug; 96 (9): 1020-1026.
7. Suma G.N., Lakhanpal M., Dhillon M., Srivastava S. Orofacial manifestations of congenital hypothyroidism: Clinicoradiological case report. J Indian Acad Oral Med Radiol 2014; 26: 111-4.

8. Singh G., Gupta N., Mythri P., Prakash A., Gupta R., Rishi R. Dental Management of Patients with Thyroid Dysfunction. J Res Adv Dent 2015; 4: 1s: 190-196.

9. Peshkova E. Mineral composition of enamel and dentin of intact teeth in patients with thyroid gland pathology in Belgorod Region, Russian Federation. Dental Students' Research. 2014; (3): 16-18.

10. Venkatesh-Babu N. S., Patel P. B. Oral health status of children suffering from thyroid disorders. J Indian Soc Pedod Prev Dent. 2016 Apr-Jun; 34 (2): 139-44.

11. Vitalle M.S.S., Weiler R.M.E., Niskier S.R., Braga J.A.P. Delayed tooth eruption in an adolescent with hypothyroidism. Rev. paul. pediatr. 2012 Dec; 30 (4): 613-616.

12. Chandna S., Bathla M. Oral manifestations of thyroid disorders and its management. Indian J Endocrinol Metab. 2011 Jul; 15 (Supp12): S113-S116.

13. Briones-Gonzalez M.J., Esquivel-Hernandez R., Ruiz-Rodriguez M.S., Moncada-Mendoza M.T., Pozos-Guillen A.J., Garrocho-Rangel J.A. The playroom: A complement of the University Pediatric Dental Clinic. Revista ADM 2016; 73 (1): 44-48.

14. Sexton T., Croll T.P. Anterior crossbite correction in the primary dentition using reversed stainless steel crowns. ASDC J Dent Child. 1983 Mar-Apr; 50 (2): 117-20.

15. Sivaharini S., Rakshagan V., Dhanraj S., Jain A.R. Knowledge, attitude, and practice on oral hygiene status in cretinism patients. Drug Intervention Today. 2018; 10 (11): 2215-2218. 